\title{
On the relationship of the extrema of lunar-solar tidal influences and seismic events
}

\author{
Elena Bataleva $^{1, *}$, Ksenia Nepeina ${ }^{1}$ \\ Research Station of the Russian Academy of Sciences in Bishkek, 720049, Bishkek, Kyrgyzstan
}

\begin{abstract}
The paper considers experimental data obtained at stationary and regime points of magnetotelluric monitoring on the territory of the Bishkek geodynamic proving ground (Northern Tien Shan). The studies performed indicate the relationship of variations in the electromagnetic and seismic fields, lunar-solar tidal effects, seismic regime with the processes of fracturing. The results of the time-frequency analysis of the response of the geological environment to earthquakes in the electromagnetic field are presented, the features of manifestation depending on the location of the hypoand epicenters of seismic events and their magnitude are considered. A number of responses in geophysical fields to remote and regional earthquakes of 2010-2020 with an energy class from 8 to 12 and their relationship with the extremes of lunar-solar tidal effects are considered.
\end{abstract}

\section{Introduction}

To date, a number of scientists support the idea of the relationship between earthquakes and variations of lunar-solar tidal effects - N.N. Volodichev, A.N. Podorolsky, G.P. Tamrazyan, C. Davison R.B. Hoffman, D. Emter, F.W. Klein, C.G. Knott, A. Ryall, T.H. Heaton, A. Polumbo, R.E. Weems. However, there are studies whose authors have a different point of view - T.H. Heaton, L. Knopo, J.F. Simpson, S. Shlien, H. Tsuruoka, J.E. Vidale, D.E. Willis. The works of T. Eaton are very interesting in this respect, since in the first of them he claims about the influence of lunar-solar tides on seismicity established by him, and in the second, using an extended data set, he denies the existence of such a relationship. Thus, at the moment there are enough works indicating both the relationship of the frequency of occurrence of seismic events of different energy classes with the periodicity of lunar-solar tidal effects, and the effect of a tidal wave on the spatial distribution of earthquake foci [1-3]. However, since studies on the connection of lunar-solar tides with natural catastrophic processes are ambiguous and controversial, from our point of view, additional information can shed light on the solution of this issue.

Studies to research the response in geophysical fields of processes associated with deformation of the Earth's crust under the influence of lunar-solar influences have been carried out on the territory of the Northern Tien Shan (Bishkek geodynamic proving ground (BGPG)) since the end of the last century. Monitoring observations carried out by the BGPG include electromagnetic, seismological, gravimetric, GPS observations - solar tidal influences.

\footnotetext{
* Corresponding author: elena.bataleva@gmail.com
} 
It is also possible to obtain data on the stress-strain state of the lithosphere of the Northern Tien Shan, caused by the tidal force of the Moon and the Sun. The stressed state of the geological environment, in turn, is one of the most important characteristics that determine both the influence of tidal forces on different-scale and various seismic processes, and the course of geodynamic processes in general.

\section{Methodology for conducting monitoring observations}

At the Research Station of the Russian Academy of Sciences, the work by the methods of magnetotelluric (MT) and magnetotovariational (MV) sounding is carried out with Phoenix Geophysics MTU-5 equipment, for mathematical processing of field data, the SSMT-2000 program developed by specialists of the same company is used. The processing program can be executed in two modes - "local" and "remote reference", it is based on the correlation method, and not narrow-band filtering, which is widely used in other software packages. First, the cross-correlation functions of all field components are calculated, then the Fourier transform is carried out, as a result of which power spectra are obtained in a wide frequency range, which are then recalculated into the components of the impedance tensor and the Wiese matrix.

A feature of MT sounding in mountainous conditions is the fact that the quality of the recorded MT-field components is determined not so much by the presence of industrial noise as by the presence of nearby thunderstorms or wind and microseismic noise. To suppress noise and smooth the transfer functions, the MT-Corrector program is used, developed by the employees of the geophysical company "North-West", Moscow. In the in-depth processing procedure for the final selection of impedance estimates, all solutions are used with a separate analysis of impedance and admittance estimates, and then the most "noisy" estimates are rejected, followed by combining and smoothing the most reliable solutions for the resulting curves.

The MT-Corrector software package allows you to check dispersion relations of the second kind, which characterize the relationship between the apparent resistance and impedance phases [4]. MT-Corrector allows you to calculate phase curves from the corresponding values of the frequency dependences of the impedance modules. The value of the spline deviation of the observed and calculated phase curves characterizes the degree of fulfillment of the dispersion relations. The verification of the fulfillment of the dispersion relation of the second kind showed that for all points of MT monitoring it is performed in a significant part of the frequency range of observations with minimal correction of impedances (apparent resistances). The use of this approach in the processing of MT data helps to reduce the RMS residual when performing $2 \mathrm{D}$ inversion and to improve the accuracy when constructing timefrequency series (TFS).

To analyze the monitoring data, the author's method of azimuthal MT-monitoring is used, which allows to identify abnormal changes in apparent resistivity and impedance phase, and to determine the directions corresponding to their maximum positive and negative variations (compression and extension axes) [5]. The azimuthal characteristics of the variations of the impedance tensor components are presented in the form of TFS. the field data was interpreted using the author's method

The analysis of the results obtained for the relationship with the seismicity of the region is carried out using data from the digital networks KNET and KRNET (http://www.gdirc.ru/lki/napravlenija-issledovanij/sejsmologicheskie-nabljudenija;

https://seismo.kg/ru). For the study, an area was selected where the sensitivity of the KNET network is sufficient to register events of energy classes according to Rautian $\mathrm{K} \geq 7$ (magnitude at least 1.7 ) with practically no gaps. 


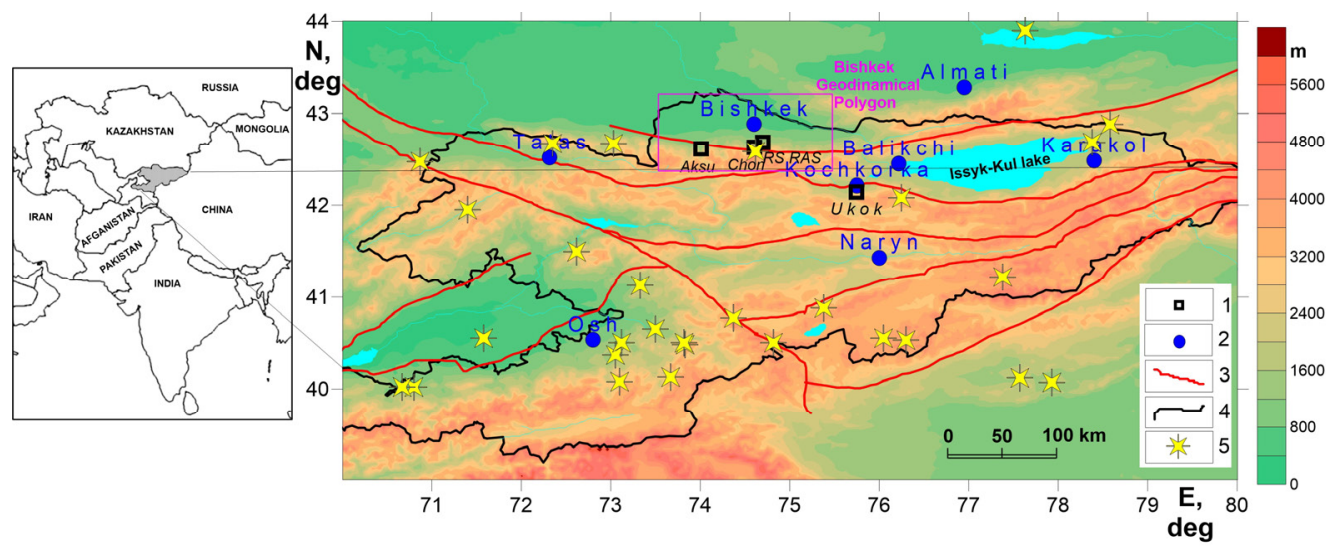

Fig. 1. Location map of stationary points of the MT-monitoring and point DMT Ukok, performed on the territory of the Central Tien Shan: 1 - stationary points of MT-monitoring and point DMT Ukok; 2 main settlements; 3 - regional faults; 4 - border of Kyrgyzstan; 5 - 5 - seismic events that occurred during the registration at the point of DMT Ukok.

Gravitational tides are constantly recorded using a Scintrex CG-5 Autograf gravimeter installed on the territory of the Research Station of the RAS in a specially prepared adit.

We considered two main types of tidal variations in the vertical component - diurnal and semidiurnal. To calculate the lunar-solar tides, we used the TIDE_3.exe program, which can be used to calculate the lunar-solar tidal effects. As a result of the program operation, in the TIDEALL.txt file (lunar-diurnal variations) for each hour, four values for the tide curve are obtained: the eastern component $(\mathrm{Au})$, the northern component $(\mathrm{AV})$, the vertical component (An), and the modulus of the total vector (A). Basically, semidiurnal and diurnal tidal waves are calculated for the Earth with the ocean and for the solid Earth (excluding the ocean). However, the calculated curve will differ from the observed one due to many factors, such as the type, thickness and structure of the Earth's crust. The discrepancies between the observed field and the calculated curve can be removed using the "GS-project program for primary processing of the data of the gravity field registration" written by E.V. Vorontsova. The program was created within the framework of the Project and is intended for primary processing of the gravitational field registration data using the Scintrex CG-5 gravimeter installed in an adit on the territory of the Research Station of the RAS. The program provides the ability to link the file of the calculated vertical component of the lunar-solar tide to the gravimeter record and divide the measured gravitational field into tidal and non-tidal components (Fig. 2) [6].

\section{Results of monitoring observations}

We have considered the results of the time-frequency analysis of the response of the geological environment to earthquakes in an electromagnetic field, paying special attention to the features of the manifestation of such a response depending on the location of the hypo- and epicenters of seismic events and their magnitude. A number of responses (Fig. 2-4) in geophysical fields to remote and regional earthquakes of 2010-2020 with an energy class from 8 to 12 and their relationship with the extremes of lunar-solar tidal effects are analyzed. The results obtained correspond to the hypothesis of the redistribution of fluid between the systems of fractures that penetrate geological objects and have different orientations, the restructuring of which is manifested in a change in a number of characteristics of the environment, in the 
formation of anomalies in geophysical fields, as well as in the appearance of anisotropy of rock properties.

\section{Vertical component of the Iunisolar tides An}

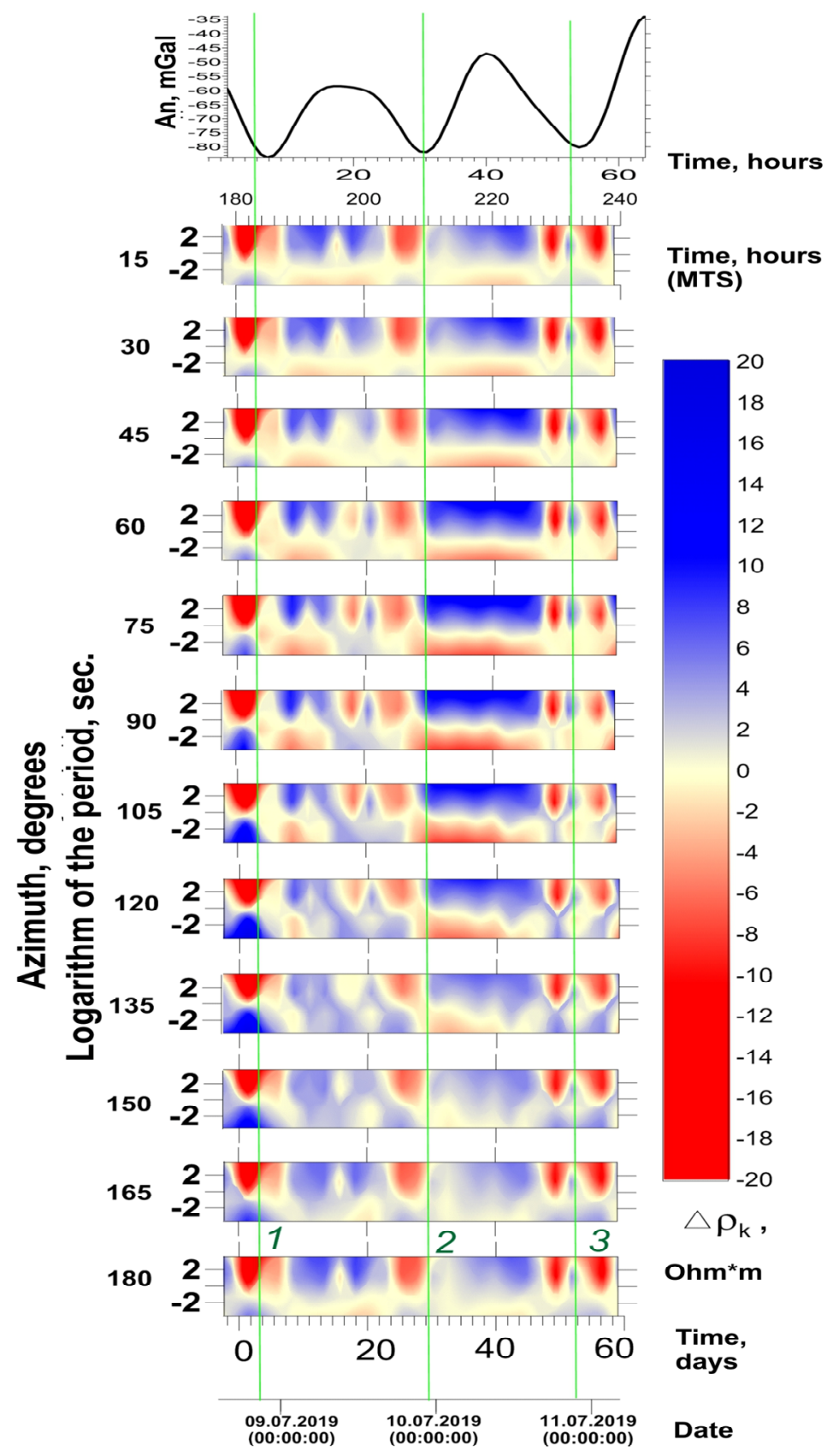

Fig. 2. The result of observations at Ukok-2 on 07.08.2019 - 07.11.2019. The upper graph is the vertical component of the lunar-solar tides, the lower sections are the MTS time-frequency series plotted with a $15^{\circ}$ step. Green lines with numbers show the time of registration of earthquakes. 


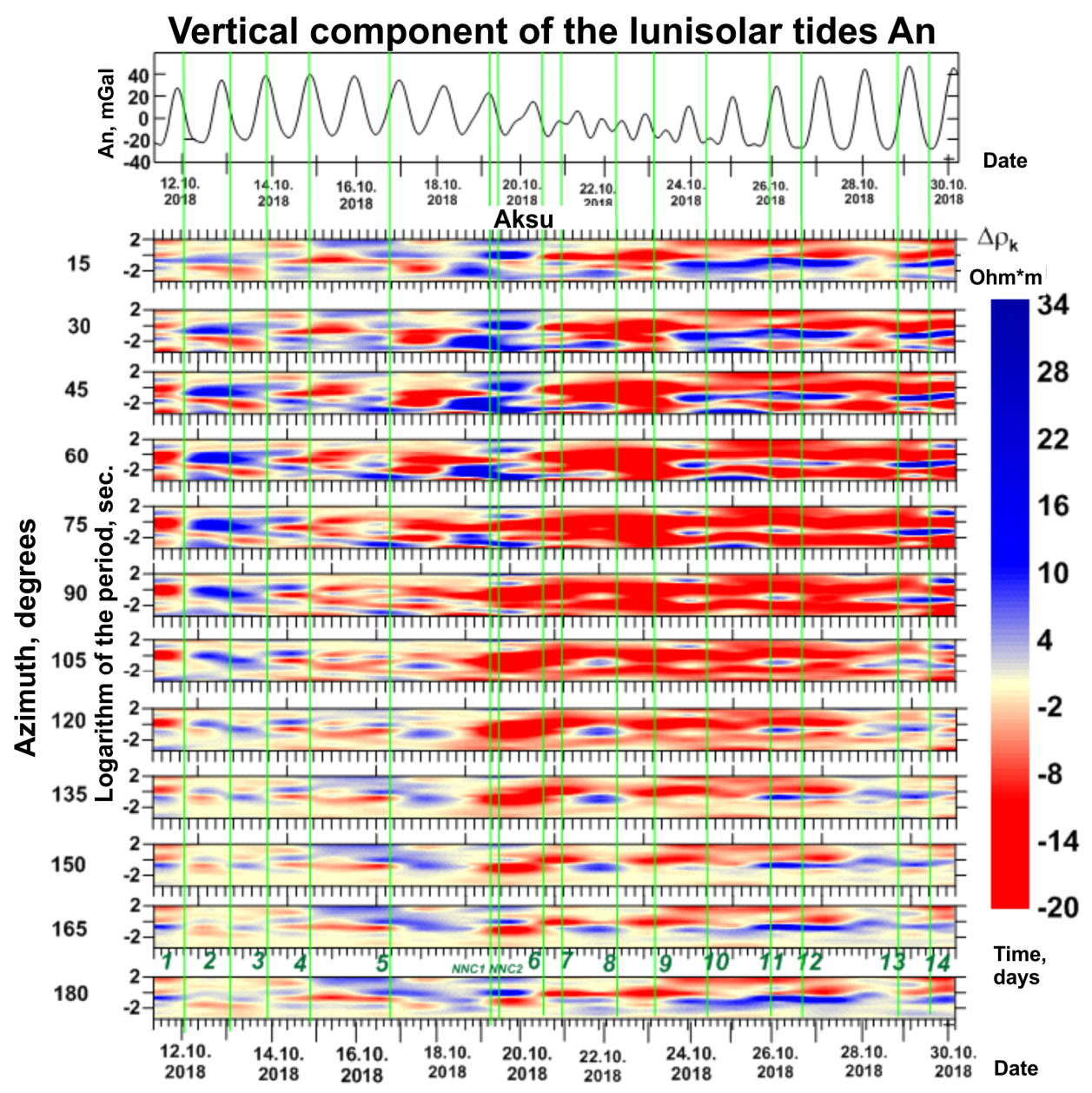

Fig. 3. The result of comparing lunar-solar tides and time-frequency series at the stationary station Aksu on 12.10.2018-30.10.2018. The green numbers indicate the earthquakes.

Good agreement between the calculated results obtained with the tide.exe program and the observed data was obtained. The analysis of correlations between variations in apparent resistivity and lunar-solar tides indicates the existence of a relationship between these phenomena. The low level of the values of the correlation coefficients in a number of observation points indicates that, in addition to tidal effects, tectonic sources of deformations are constantly acting in deformation processes. A causal relationship between lunar-solar tides and variations in the electromagnetic field is shown. The characteristics of the correlation fields indicate that sources of deformation processes, in addition to periodic tidal effects, are sources of a different nature. This may also be due to the peculiarities of the tectonic and geological structure of the study area, for which the analysis of the relationship of geodynamic processes with lunar-solar tides is carried out.

In the diagrams of the correlation of variations in apparent resistivity between the components of lunar-solar tides and changes in baseline lengths, there is significant similarity, both for point "4", which is located directly above the Shamsi-Tyundyuk fault zone, and for points located in other geological and tectonic conditions, although the difference in the morphology of correlation fields for different observation points is significant and is probably 


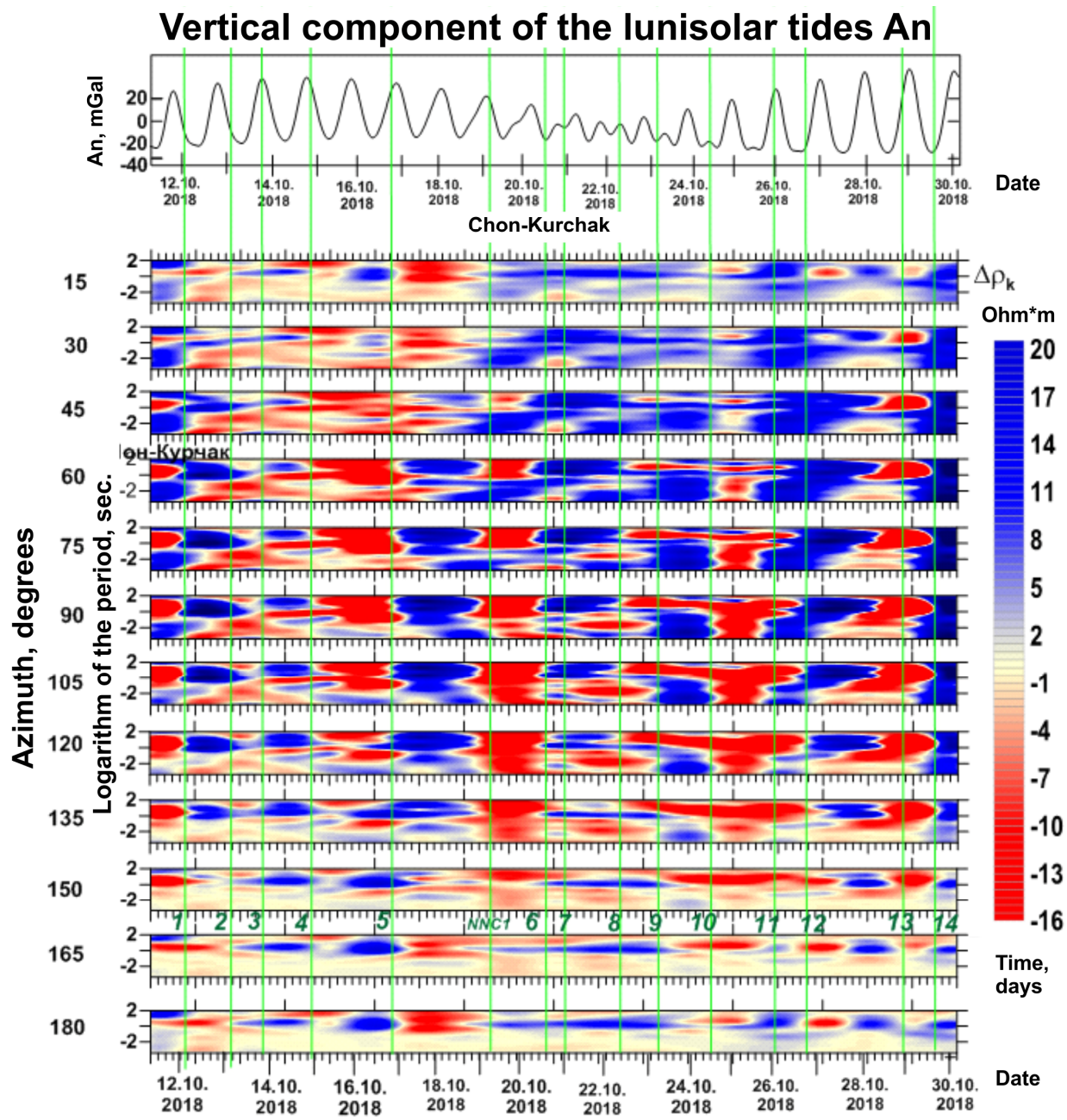

Fig. 4. The result of comparing lunar-solar tides and time-frequency series at the stationary point ChonKurchak on 12.10.2018-30.10.2018. The green numbers indicate the earthquakes.

due to the presence and orientation of large geoelectric structures, the characteristics of electrical conductivity of which are determined by the distribution of pore-fractured fluids. The correspondence between the "current" directions of compression-extension with seismotectonic deformations has not been established.

A database of time series of MT-monitoring observations was created in a format convenient for the subsequent analysis of these data for two stationary stations for the period from 2003-2020, within the framework of the existing MT-monitoring database. In terms of the duration of continuous observation series, the complexity of the methods used and the density of the observational network, the geodynamic test site created by the Research Station of the RAS currently has no analogues in the world [7]. Monitoring magnetotelluric observations have been carried out from 2003 to the present using the Phoenix MTU-5D station at stationary (Aksu and Chon-Kurchak), profile (Kentor minipolygon) and security points.

The system for collecting data and processing information for magnetotelluric monitoring allows you to collect and accumulate data from a variety of monitoring points of observation - 
stationary, regime, profile (Fig. 1). To study geodynamic processes in the Earth's crust and upper mantle based on the calculation of transfer functions between the components of the magnetotelluric field with a high temporal resolution in order to study their temporal dynamics. The end result of such monitoring, from a formal point of view, is a collection of time series of various data. In the practice of monitoring geodynamic processes, statistical methods of data analysis are widely used. In particular, correlation analysis is used to determine the degree of relationship between the observed data series. time series are formed, which are used to study changes in recorded parameters over time and to highlight anomalies associated with the preparation of strong earthquakes. The programs are designed for visualization, processing and analysis of time series. They have a user-friendly interface. They implement arithmetic, statistical and other functions for working with time series. It is possible to edit pictures (graphs) on the screen, save and print them.

\section{Conclusions}

Thus, it can be stated that seismic events and variations in lunar-solar tides are interrelated. We considered earthquakes of energy classes less than 12; therefore, we can conclude that confinement to the extremes of lunar-solar tidal impacts is more characteristic of weak seismic events.

In addition, the studies performed allow us to assert the importance of taking into account the peculiarities of the geological structure of those objects of study for which an analysis of the relationship of geodynamic processes with lunar-solar tidal effects is performed.

At the same time, the results of studying the relationship between lunar-solar tides and modern geodynamic processes in seismically active regions are ambiguous and require additional study.

The work was carried out within the framework of the state assignment of the Research Station of the Russian Academy of Sciences on the topic AAAA-A19-119020190063-2.

\section{References}

1. V. A. Nicolaev Moscow Science, 236 p. (2003)

2. S.V. Goldin, V.Yu.Timofeev, M. van Ruymbeke, D.G. Ardyukov, M.E. Lavrentiev, R.G. Sedusov Physical Mesomechanics 11(4), 81, (2008)

3. Yu. V. Antonov Proceedings of higher educational establishments geology and exploration, 3, 51, (2018)

4. M.N. Berdichevsky, V.I. Dmitriev Models and methods of magnetotellurics Springer Berlin, 563 p. (2008)

5. E.A. Bataleva, V.Y. Batalev, A.K. Rybin Izv. Phys. of the Solid Earth, 49(3), 402 (2013)

6. Yu. V. Antonov, Ye. V. Vorontsova Proceedings of higher educational establishments geology and exploration, 3, 63, (2012)

7. E. Bataleva, A. Rybin, V. Matiukov Data, 4(3), 99, (2019) 